\title{
Dos Manuscritos Inéditos de "El Pensador Mexicano"
}

\footnotetext{
$\mathbf{0}$ BRaN en mi poder los dos manuscritos de "El Pensador Mexicano" (J. J. Fernández de Lizardi) que se publican a continuación, los cuales, que yo sepa, no fueron hasta el presente dados a la estampa. Uno de ellos lleva la fecha de 1812 ; el otro, la de $1816 .{ }^{1}$ En el primero hay una nota que dice:

El dia $1^{\circ}$ de diciembre de 1812 debió salir este periódico impreso, pero no se verificó a causa de que el gobierno mandó arrestar al Autor, y suspender la libertad de la imprenta por medio del bando expedido en la misma semana.
}

Es probable que el artículo a que se refiere "El Pensador" estuviese, como él lo asegura, en manos del impresor el $1^{\circ}$ de diciembre; pero si era así, el manuscrito que poseo es evidentemente de una fecha un poco posterior, porque los dos incidentes a que se refiere el autor - la suspensión de la libertad de la imprenta y su propio encarcelamiento- no tuvieron lugar hasta el 5 y el 7 de diciembre, respectivamente. Por consiguiente, parece verosimil que "El Pensador" hiciera circular subrepticiamente -como ocurrió con el resumen del prohibido $4^{\circ}$ tomo de su Periquillo Sarniento- 2 una copia o copias de este artículo, cuando él ya estaba en la cárcel.

El propósito de "El Pensador", en este documento, era contestar un folleto publicado por un individuo que firmaba "El Preguntón", ${ }^{3}$ en el cual éste advertía que ciertas proposiciones de "El Pensador" " para terminar con la rebelión, se habían hecho con el sólo propósito de ayudar a los insurgentes $y$, al final de cuentas, de darles la victoria. "E1 Pensador", que vió en la nueva Constitución de 
Cádiz una forma de gobierno encaminada a reconciliar las diferentcias entre España y sus colonias, negó rotundamente $-\mathrm{y}$ en esto creo que enunció con toda sinceridad su actitud politica en" aquel entonces- la acusación de "El Preguntón".

El manuscrito de 1816, que está dirigido al "Señor Diarista" - probablemente el editor de El Diario- es una fábula en que se ridiculiza a los que pronuncian opiniones en cuanto a cosas de que nada saben. Hay también en este manuscrito un anuncio de la próxima publicación de El Periquillo Sarniento. Anticipándose a una crítica injusta de su novela, "El Pensador" dirige la moraleja de su fábula a los que pudieran condenar su obra sin haberla entendido o leído.

J. R. Spell

I

[1 1 f. $]$

El Pensador Mexicano *

Namque hoc tempore, obsequinm amicos, veritas odium parit. Terent. 5

Traducción del Autor

En este tiempo maldito

nos segamos de manera

que aborrecemos de muerte

al que la verdad nos muestra.

Señor Preguntón: Las respuestas que V. exige del amigo de la Patria mejor las exigiera de mí, pues (en la parte que me toca) yo he fomentado las irónicas y maliciosas dudas que le escuezen.

No deteniéndome en contestar a sus insulsas chocarrerias, pasaré seriamente a responder al asunto principal, lo que no hiciera, $y$ antes viera con el desprecio que merecen tamañas calumniantes criminalidades, a no recaer éstas precisamente sobre mi acreditada conducta y patriotismo. Si, acreditada como consta por los documentos que originales paran en la secretaría del superior govierno y en la de la misma junta de seguridad. /

* El día $1^{\circ}$ de diciembre de 1812 debió salir este periódico impreso, pero no se verificó a causa de que el govierno mandó arrestar. al Autor, y suspender la libertad de imprenta por medio del bando expedido en la misma semana. 
Seguiré el método de las preguntas de V. aunque ciñéndome a la brevidad posible. En mi $n^{9} 5$, pág. $33,{ }^{6}$ llamé mediterraneo al mar que divide la América de la Europa. V. pregunta ¿si es cierto este inaudito y espantoso trastorno? Respondo: que no es trastorno ni espantoso; aunque es inaudita la opinión. $\mathrm{Ni}$ es menester que tengan almas negras como el atizado africano los que no entienden el sentido de mi afirmación.

El diccionario castellano a f. 559 dice: mediterraneo lo que está en medio o entre dos tierras; es así que el mar que V. llama océano está en medio y entre dos tierras, quales son la América y la Europa, luego este mar se debe llamar con toda propiedad mediterraneo. Señale V. si no, el defecto del silogismo.

Ni obsta el que por un viejo y tolerado abuso se le haia llamado océano impropiamente; los errores antiguos los han destruído las juiciosas opiniones modernas. Si no hubiera sido por éstas, todavía estubiéramos creyendo que el alma racional se infundía en el feto a los quarenta o sesenta días, lo que sirviera para deducir unos principios brutales $\mathrm{y}$ heréticos: todavía creyéramos que la tierra era el centro de los planetas, y tan fixa como la pertinacía de los peripatéticos: todavía disputáramos del ente de razón, de la materia prima, de las qualidades ocultas y de otras mil voverias que sólo sirben de entremeses entre los literatos.

¿Quién ha sido el que ha impugnado como error / una demostración por sólo nueba? Jamás nombraremos sin respeto los venerables nombres de un Muschen, ${ }^{7}$ de un Cartesio, de un Leibnitz, de un Gómez, de un Para, de un Nollet y de infinitos otros, cuyos descubrimientos físicos aunque nuebos han servido tanto en veneficio de los hombres.

- El haber llamado los antiguos océano al nuebo mediterraneo, no precisa a seguirlos contra el testimonio de nuestros ojos. Aquel Hércules quando llegó a Cádiz donde dizque puso sus columnas, creyó que ya no había adelante 'más tierra, que era todo agua, y por eso las inscribió con el decantado Non plus ultra, y creyendo que aquel mar no era inmenso sino infinito; le llamó océano; y por su magnitud los geógrafos le han seguido llamando del mismo nombre, metafóricamente; pero sin propiedad. 
Lea V. el diccionario citado y verá que a la pag. 598 dice: metafóricamente se usa muchas veces para expresar muchas cosas que no puede ponderarlas la lengua por su grandeza e inmensidad. Pasemos a otra cosa.

A la $7^{3}$ pregunta de V. revestida de quatro quandos intempestivos, criminales y arrastrados fuera de propósito, era menester un tomo para responderla. Desafío a V. y a otro qualesquiera $a$ un acto público literato [sic] en la Universidad de México, y siempre que me convenzan de que mis periódicos son incendiarios, protectores de la insurrección, enemigos de España o de los buenos españoles, protesto por Dios que me da licencia para escribir esto y por esta santa señal 此 del patíbulo amable

[2 v.] en que fuí redimido, que de/allí iré gustoso a la capilla y expiaré con mi vida la petulancia y veneno que se quiere suponer en mis papeles; ¡ea, sapientísimo y calumniante Preguntón! salid al frente, admitid el desafío; si lo admitís y me convencéis, yo perdiré mil vidas agradeciéndoos el desengaño; y si no, vos quedaréis entre los sabios tenido por un botarate y un criminal pedante.

Pero por no dejar de responder alguna cosa, diré que acerca de la prohibición de plantar viñas y linos, lea V. no más el Censor extraordinario impreso en Cádiz y allí veră como ha sido cierta, y allí verá como no es lo mismo permitir o disimular que conceder. Alli verá las leyes y los encargos particulares hechos a los Virreyes para que zelaran la observancia de lo contrario. Allí en fin verá mi proposición con términos auténticos, constantes e irrefragables. ¿Y es acaso lo mismo concesión libre que disimulo forzoso? En España se permitió (como en otros lugares) barrios destinados a las públicas prostitutas; si en Madrid fueron públicos y permitidos los lupanares, y ipor eso diremos que han sido lícitas en España las prostituciones? ¡O! que para escribir es menester escribir con datos constantes, y que la pluma no la mueve la pasión sino la verdad! Estudie V. un poco más lógica antes de entrar en disputa con el Pensador: de lo contrario los escudos de $V$. serán tan inexpugnables como las miserables escamas de los mextlapiques. " ¿Quién le

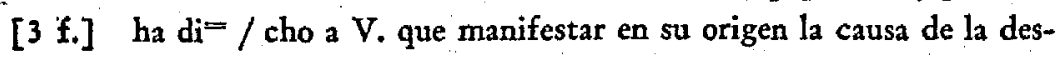

* Pequeños pésecillos cuyos débiles escamas casi son imperceptibles. 
unión de criollos y europeos es soplar el fuego de la insurrección? ¿Quién le ha dicho a $V$. que al paciente después que lo han hartado a heridas se le ha de negar hasta el consuelo de quejarse? ¡Bueno es que me azoten en la plaza y que no lo sepan en mi casa! ¡bueno es que los extranjeros y los mismos españoles uniformes y constantes haian declamado contra el mal govierno de la América, 'y que a un americano no le sea lícito sólo por ser americano decirlo a la Nación para que lo remedie y para que no se deje engañar de los aduladores intrigantes que la están haciendo creer (como dice el vulgo) en un hueso! Este si es despotismo, y (pese a V.) detestable despotismo, ignorancia, tiranía o execración, y suspiro del mismo Satanás.

Yo me he propuesto ( $y$ lo he de verificar hasta perder la vida) desengañar a la Nación, al Exmo. Sr. Virrey y a los buenos españoles, al público ilustrado y al mundo todo que la causa de la insurrección ha sido el mal govierno en la América, ha sido el despotismo, el despotismo, y otra vez el despotismo, y este despotismo no ha estado solamente en el ministerio de Indias un aliquando, ni siempre en el Palacio de México, ha estado en todas partes porque en todas partes los hombres son capaces de ser déspotas.

Sí, Nación española, sí, sabios ministros, sí, buenos ciudadanos, sí, Alemania, sí, Francia, sí, Inglaterra, sí, mundo todo; el Pensador Mexicano es más cristiano, más fiel al Rey, y mejor patriota que quanto escritor ponzoñoso sale de las prensas: un defecto tiene para los necios, y es, no ser adulador; quiere que esta herida penetrante se cure radicalmente, $y$ no que se solape, y para esto no está el remedio en la pólvora ni en el cáustico, ni en la sangría como impíamente pretende el cruel Preguntón.

No, y no, y no, y por este no moriré y será la última $\mathrm{pa}^{\mathrm{a}}=/$ labra que pronuncie. El remedio, si el tiempo lo permite, son bojas de olivo empapadas en aceyte de caridad de amor $y$ de dulzura; no sangre, no fuego, no dureza, no rivalidad, por amor de Dios, por María Santísima; acuérdense los que goviernan de la fábula del sol y el aire sobre desnudar al caminante. El aire apuró sus torbellinos, y el caminante se tiró contra el suelo y 
no lo desnudó, y el sol suavemente lo acaloró hasta el término de dejar él voluntariamente la ropa.

El Preguntón dice: (pág. 9.) truene el cañón, afilense las bayonetas, nade la tierra en sangre, y el Pensador dice al govierno, dice a los insurgentes, disputemos la justicia con plumas, no con fusiles; curemos esta herida con olivo, no con pólvora; tratemos como racionales, no como fieras; no hagamos consistir la ley en las puntas de las bayonetas. ¿Quién es más cristiano, más racional o más sensible, el Preguntón o el Pensador? respondan los cristianos, los racionales y los sensibles.

La Nación y el superior govierno están hoy más que nunca en estado de necesitar nuestras luces para el acierto de sus providencias, $y$ no de la adulación ni la mentira que entorpezca - haga ilusorias sus más sanas intenciones. Yo he descubierto la llaga en su. lugar, the hecho mal en esto? Si estoi enfermo del bazo deberé quejarme del hígado? $\mathrm{Y}$ si lo hago así ¿tendrá el médico la culpa en errar la cura? pues éste es tọdo el crimen que se me imputa.

Las Cortes a nombre de la Nación acaban de sancionar una constitución cuyo espiritu es consolidar los dos continentes, favorecer a los ciudadanos, defender sus derechos, proporcionarles la livertad individual, velar sobre las prerrogativas que les acaba de conceder en justicia, evitar todo motivo de queja y rivalidad, y hacerlos últimamente felices. $/$

[4 f.] Yo tacitamente digo a la Nación: V. M. ha dado con esta constitución la prueba más inequívoca de su sabiduría y paternal amor; al govierno digo: esta constitución se ha formado tan justa y tan cabal por estos antecedentes: ellos han sido la causa de la insurrección, y con su presencia han determinado las Cortes con acierto; conózcase el mal en su origen, mírese de dónde proviene, $y$ entonces se podrán aplicar los remedios con más tino.

Esta ha sido mi intención ante Dios $\mathrm{y}$ ante los hombres de juicio; si en esto he errado cúlpese a las Cortes que me han permitido estampar mis ideas políticas en el artículo 371 de la constitución; cúlpese a la junta de censura de esta capital que ni ha recogido mis números anteriores ni me ha prohivido continuar mis pensamientos, $\mathrm{y}$ cúlpese de una vez a la misma constitución que acabamos de jurar, a las leyes de Castilla e 
Indias, $\mathbf{y}$ a los Autores españoles que cito: éstos son los materiales con que'se va fabricando el periódico, y mientras estos testimonios no se refuten, ni V. ni quantos Preguntones hai en el mundo, serán capaces de argüirme de mal vasallo, ni calificar mis papeles de subversivos.

Yo he dicho y repito: que no canonizo ${ }^{-1}$ a insurrección, pero tampoco soy tan dévil que por un afectado patriotismo como muchos, o por un corazón envenenado como otros, deje de manifestarle al superior Govierno con mucho remordimiento las causas del mal, ni de insinuarle los remedios que me parezcan eficaces.

¡Ojalá que este arbitrio huviéramos tenido al principio fatal de la revolución; quizá se huviera atajado el $\mathrm{mal}$ en su infancia.

$\mathrm{Si}$ a V. hace tanta fuerza que haia declarado las causas de la insurrección y le parecen nuevas en el mundo, lea / quales fueron los motivos de las frecuentes rebeliones en el imperio de los Persas, y cotéjelas con la presente, a ver si se parecen.

Si tiene por blasfemia el que yo en un disimulado hipótesi haia hablado de un armisticio, y lo juzga por inútil, lea entre infinitos el que se hizo por un año entre los atenienses y los lacedemonios, $y$ verá que produjo una paz duradera; traigo este exemplar porque para él hubo sus opositores como para el nuestro. Si señor; si, un tal Cleón, y un tal Brasidas se oponían fuertemente a las treguas porque no querían la paz, ¿y por qué? por que el uno era un lobo encarnizado con la humanidad, $y$ el otro un egoísta que deseoso de hacer su suerte ansiaba por ocasiones de acrecentar sus triunfos a costa de la sangre de los hombres; ambos murieron desastradamente. iJusto castigo del iniquo!

En su primera pregunta dice V. que ęsi se le da crédito a un escritor, v. g. al autor del juguetillo que impugnó el elogio al Sr. Calleja por malo, por inmetódico, por insulso, no por referirse su autor al Sr: General se deprime el eminente servicio del Sr. Truxillo y su esforzada división, etc., y que ia este hombre se le podrả decir, tus noticias saven a Rayón, huelen a Morelos? 
$Y$ yo digo: a un hombre para quien no hai más medio que el rigor, la muerte y la desolación; a un hombre sanguinario que desea que truene el cañon, que se afilen las bayonetas y que nade la tierra en sangre ino se le podrá decir; tus expresiones saven a Nerón, huelen a Calígula, olizcan a Napoleón y apestan a Lucifer? Sí, sin duda, porque estas malditas intenciones son los datos más seguros de un alma vil, y de un corazón de de-

[S f.] monio, porque de su práctica no se sigue ni honra a / Dios, ni provecho al Rey, ni bien a la Patria. Lo primero, ni honra a Dios, porque de todos los que mueren en una batalla, ¡Dios sabe los que se salvarán! $Y$ así en los que se condenan (si no se ve por el atributo de la divina justicia) se pierde el fruto de la redención, y esto no cede en su honra. No es provecho del Rey, porque al Rey no le puede aprovechar un reyno destruido $y$ aniquilado. No en bien de la Patria, porque para la Patria no es bien asolarla ni teñirla con la sangre de sus hijos. Conque tal deseo y tal execución sỏlo puede ser satisfactorio a los crucles, v. g. .... Le haré a V. unas reflexioncillas por si fuere de los que sujetan el discurso a la razón.

El cuerpo político se parece en sus enfermedades y curaciones al cuerpo humano; esto sentado, pregunto: ¿a uno que padece cámaras biliosas será bueno darle un vaso de vino? No señò, que la naturaleza está irritada, el vino es irritante, y será fomentar el mal; lo que seguramente conviene son los dulcificantes y calmantes. He aquí nuestro caso, tres años contamos de enfermedad: el superior govierno ha apurado sus diligencias por todas partes, han corrido ríos de sangre, han subido las llamas del fuego hasta los cielos: ha tronado el cañón, se ban afilado las bayonetas, ba nadado la tierra en sangre de nuestros hermanos, que es lo que V. quiere; bien, $y$ después de tres años ¿cómo se siente el enfermo? peor que peor; luego no es éste el remedio. ¿Quiénes han muerto $y$ están muriendo en esta época desgraciada? Americanos, europeos, indios, castas, blancos y negros, ¿y qué son todos éstos? españoles, ¿y de quién es este Reyno? de España, ¿y las minas? de España, ¿y los campos? de España, ¿y los pueblos? de España, ¿y todo? de España, o por /

[S v.] mejor decir la España misma: luego al fin, al fin España pierde, y pierde más quando más tarde gane, y éste es el juego de la 
gana pierde, y mientras más truene el cañon, mientrás más se afilen las bayonetas, y mientras nade la tierra en sangre más pronta y más irreparable es su pérdida. ¡Política infernal hacer pedazos lo mismo que apetezco!

Dos hermanos riñen por una capa: cada uno la ase de un extremo; después de la refriega se halla cada uno con un manojo de tiras en la mano; pregunto ¿qué será mejor, atizarlos en su coraje para que rompan la capa, o procurar apaciguarlos para que quedando entera pueda servirles a los dos? Pues éste es el caso: hemos afianzado la capa unos por un lado y otros por otro: la capa ya está hecha pedażos, y el Pensador dice: espérense, callense, veremos cómo nos sirve a todos la capa, porque si no, se la acaba de llevar el diablo. Este es mi pecado, ¿merecerá perdón? $Y_{a}$ se ve que dice el refrán, que quien mete paz se saca lo más.

Muy bien está que San Pablo en la epístola a los Romanos, diga hablando del Príncipe: Non enim sine causa glaudium portat. ¿Y qué quiere decir esto? que el Príncipe tiene autoridad y fuerza para castigar a los delincuentes. En esto estamos, ¿quién lo ha negado? pero yo no veo que en ésa ni otra epístola prohiva Dios a los Reyes el intentar los caminos de la paz, antes dice: baced quanto esté de vuestra parte por 'tener paz con todos.

V. desea que truene el cañón y nade la tierra en sangre y que no quede hombre a vida, no por amor del Rey ni de la Patria, sino por odio, por venganza y por miédo: por eso calumniosamente asegura que mi objeto es dar tiempo a que la insurrección se perfeccione... y lo deguellen con ventaja. /

Habla V. sin politica, sin caridad y sin reflexión. ¡Miserable! pues en este caso, ¿nuestro Govierno es tan dévil que no había de tomar sus providencias oportunas de precaución? jno se robusteceria también de gente, armas y dinero por lo que pudiera suceder? tho se pedirian sus rehenes estimables a los insurgentes para obligarlos a la observancia de la capitulación? no se les señalarían los linderos o cotos de donde no pudieran pasar? ¿Y no se tomarian todas las medidas adaptables $y$ precisas en tales circunstancias? ¿Pues cómo va V. asegurando contra mí, tamaña calumnia? pero ya lo dixe: habla $\mathrm{V}$. sin conocimientos políticos, sin caridad y sin reflexión. 
Amigo: de la abundancia del corazón babla la boca, (también lo dice el Espíritu Santo). El hombre cruel y sanguinario habla sanguinariamente. El tirano, el vengativo, el que no ama a su Patria, a su próximo, y el que aborrece a sus enemigos, es el que desea a todas horas que traene el cañón y que nade la tierra en sangre de los mortales. No es esto por cierto la doctrina de Jesucristo.

El Espíritu Santo (vea V. cómo yo también sé citar textos) dice: "amaos mutuamente como hermanos verdaderos, y procurad anticiparos unos a otros en las señales de obsequio; desead toda felicidad a los que os persiguén, hablad bien de ellos $y$ no volváis mal por mal. No hagáis mal al que os lo ha hecho; dad de comer y vever a vuestros enemigos si necesitan de este favor; procurad finalmente que la malicia de vuestros contrarios no sea mayor que vuestra constancia y amor, que los favores que les hagáis sean superiores a los agravios recibidos." (S. P. ad Rom., cap. 12). Perdona a tu próximo que te ha dañado, y entonces, [6 v.]. quando / tú pidas perdón se te perdonará. (Ecc ${ }^{9}$ cap. 28, v. 2). ¿Pero para qué me canso si no hai precepto más recomendado por el mismo Jesucristo? Por San Mateo nos dice: si perdonáis a los hombres sus injurias, se os perdonarán vuestros pecados, si no, no os perdonará vuestro Padre Celestial. Por San Marcos: Quando vayáis a orar, perdonad primero a vuestro enemigo para que vuestro Padre os perdone. Por San Lucas: Amad a vuestros enemigos y haced bien a aquellos que os han aborrecido; bendecid a los que os maldicen, y honrad a vuestros calumniadores; si alguno te diere una bofetada ponle la otra mexilla, y si alguno te quita el vestido dale la túnica o camisa. Haz con los hombres lo que quisieras que ellos hicieran contigo. ¿Qué gracia harás en amar a los que te aman. Qualesquiera pecador hace lo mismo: y así amad a vuestros enemigos, hacedles bien y socorredlos sin ningún interés... Por San Juan: Este nuebo mandamiento os doi, esto es, hoy lo mando nuebamente que os améis unos a otros como yo os he amado. Este es mi precepto, que os améis como os he amado. Esto os encargo, que os améis unos a otros; si el mundo os aborrece, sabed que primero me ha aborrecido a mí.

Al mismo Judas trató el Señor, y hasta la hora de su muerte lo recomendó con su exemplo la caridad y el amor a nues- 
tros enemigos; quando acabando los judios de perpetrar el más sangriento deicidio, no sólo los perdona, sino que pide a su eterno Padre los perdone disculpándolos con su ignorancia. Pater ignoca [sic] illis necium quid faciunt. ${ }^{8}$ iLe parece a V. dura esta doctrina? también a los hereges les parece; en ellos no me escandaliza, pero sí, me horroriza oír decir a un Cristiano a voca llena: truene el cañon, afilense las bayonetas, nade la tierra en sangre! ¡Cruel! después de tres años de exterminio; des $=$ / pués de tres años de la guerra más sangrienta y desoladora que han visto los siglos; después que las esmeraldas de los campos se han convertido en rubíes con la sangre de nuestros hermanos, ¿aún no se sacia la rabiosa sed de un tigre humano? ¿aún quiere que nade este Reyno en el rojo licor de sus semejantes?

No Dios mío: no, no, no lo permitas: no te irrites por las imprecaciones de este bárbaro; embaina Señor, embaina ya el azero de tu justicia vengadora, sean por sacrificio de nuestras culpas los castigos de los malos y los incesantes ruegos de los buenos. Satisfácete Señor, desenójate, no atiendas a la multitud de nuestras culpas, sino a tu infinita misericordia; no permitas se pierda más con la guerra que nos devora el fruto de tu redención en las almas de los que en ella mueren.

Y tú, Virgen Santísima, dulcísima María, querida Madre nuestra, acuérdate Señora, que en ese cerro de Tepeyac nos viniste a convidar por madre; si, tú, benigna y piadosa nos admitiste por tus hijos, nos ofreciste tu maternal amparo; tú reciviste este Reyno bajo de tu tutela y protección; tú no quisiste hacer favor igual a ninguna otra nación del universo; Non fecit taliter omni nationi: podemos gloriarnos, sí; podemos gloriarnos justamente de que aunque malos somos tus hijos predilectos. $\mathrm{Ea}_{\mathrm{a}}$, pues, fuente de dulzura y de piedad, amable madre de mi corazón, vuelve a nosotros esos tus ojos misericordiosos; mira tu patrimonio teñido con la sangre de tus hijos; mira el pueblo que elegiste para tu herencia envuelto entre la rivalidad, el odio $y$ la venganza. En tu novena estamos, madre mía; no duermas Señora, date prisa, levántate del trono de tu gloria que tu Nación perece; anda, Señora, y como otra graciosa Ester ruega, porfía y llora ante el divino Asuero para que / revoque el fatal decreto de la total ruina que nos amenaza; suplícale que alumbre a los disidentes; que ilumine al govierno; que mitigue nuestras pasio- 
nes, que este año de 12 finalize entregado a las dulzuras de la paz.

No permitas, Señora por más tiempo que truene el cañón, se afilen las bayonetas, ni que nade la tierra en sangre de tus hijos; ilumina nuestros entendimientos; une nuestras voluntades para que nos hagamos acreedores a la dulzura de la paz que [no] nos puede proporcionar la guerra. Nulla salus bello pacem te posumus omne. ${ }^{9}$

Concluí, Sr. Preguntón, añadiendo que su papel es incendiario, y que merece que se recoja no sólo por la Junta de Censura como irritante, sangriento y calumniante, sino lo que es más, por el tribunal de la fe respecto a contener proposiciones impías, escandalosas, vertidas con espiritu de venganza, opuestas diametralmente a las máximas del Evangelio, $y$ apoyadas con impropiedad con un texto de la sagrada Biblia. Si volviere $V$. con sus criminales y calumniosas preguntas, no irá por la respuesta a Roma, pues la oirá muy breve de la pluma del Pensador.

[1 f.] Señor Diarista: vaya ese envueltito para su periódico.

Allá en tiempo de entonces caminaba un gañán con su jumento departiendo en buena paz y compañia sobre quién de los dos era más tonto. Entre los alegatos que el gañán hacía a su favor para probar a su compañero que era menos bestia que él, le decia: mira, tú, al fin eres un burro, que andas en quatro pies, y si no es por un rarísimo accidente, como el presente, no sabes hablar, ni tienes razón, ni comes pan, ni te vistes, si yo no te cubro el lomo con una albarda sucia y destripada; quando yo, por el contrario, como pan, me visto, aunque sea mi gabán, gregüescos y alpargatas, hablo mucho, y por último tengo razón, $\mathrm{y}$ soy un hombre que ando sobre mis dos pies $\mathrm{y}$ más derecho que un malacate. El jumento al escuchar estas cosas miró al cielo, sacudió dos o tres veces las orejas, levantó la jeta supe-

[1v.] rior/y mostrando unos dientes anchos, amarillos $\mathrm{y}$ fornidos, comenzó a rebuznar alegremente (porque reirse no le era permitido). Entonces el gañán, que entendió la burla, lleno de có- 
lera le dixo: arre, burro maldito, animal tonto, estúpido y majadero: ¿cómo te atreves a burlarte de un hombre en su presencia? Advierte que si me enfado, te ataré a un palo y te quebraré las costillas a garrotazos. Eso si podrás hacer, dixo el asno, porque tienes superioridad sobre mí; pero aunque lo hagas no probarás con ello que eres menos necio que yo. Pues que, epiensas que porque comes pan, te vistes, hablas mucho, $y$ andas en dos pies, eres mui hábil? Te engañas. ¿Quántos hay que hacen lo mismo que tú, y son tan burros como yo? Esas / qualidades, de por si, no prueban, no digo talento superior pero ni simple racionalidad. Los perros comen pan, los monos se visten o los visten, los loros hablan, y los gallos andan sobre dos pies; y sin embargo no pasan de unos brutos. Conque señálame otra qualidad más precisa que pruebe tu talento, y de no, en mi concepto quedarás igual a los burros aunque te pese $y$ me mates a palos.

$Y_{a}$ no te he dicho, bestia, que tengo razón y soy hombre, dixo 'el gañán. Es cierto, contestó el burro; pero no lo es menos el que no sabes o no quieres usar de ella muchas veces, $y$ en éstas eres lo mismo que yo; porque lo propio es carecer de razón, que no hacer uso de ella, $y$ esto te sucede a ti y a mil de tus semejantes con frecuencia, igualándose entonces a nosotros/ con esta vergonzosa diferencia, que si el burro yerra, yerra como irracional y no como hombre, y el hombre quando yerra, casi siempre, yerra como burro; esto es: como si no tuviera razón. Días pasados te oi decir que no te haria un gabán de paño francés si te lo dieran dado. Es verdad, dixo el gañán, como que es el peor paño que se trabaja en Europa. ¿Pero cómo sabes eso? replicó el asno; porque desde que te conozco no te he visto vestir sino de sayal, de xerga y de camuza, y me parece que en tu vida te has puesto un gabán ni una montera de paño. Así es, decía el gañán; yo ni conozco el paño francés; mas un amigo mío dice que no sirve, y por eso lo aseguro yo. ¿Qué te parece! exclamó el borrico. ¿'Ya ves como tú eres un hombre, pero un hombre que no sabe usar de la razón que el cielo le concede? / ¿Conque sólo porque tu amigo dice que el paño francés no sirve, ya tú lo aseguras tenazmente? ¿ $Y$ dime, ese tu amigo es texedor? No es sino albañil. Eso es peor, dixo el burro; si el voto fuera de un inteligente, ya tu deferencia se apoyaba sobre algún fundamento razonable; pero decidirte a condenar el paño francés 
por sólo el voto de un albañil que lo conoce tanto como tú, es la mayor prueba de tu gran capacidad; mas no te desconsueles, tienes muchos compañeros, que pensando a lo burro de dos pies, reprueban muchas obras literarias sin entenderlas, y mil -veces sin haberlas visto por el forro, llevados quizá del voto de un albañil, $y$ esto se llama acreditarse de necios.

No sé en que pararía la disputa, pero si creo que el burro

[3 v.] estaba cer-/ ca de convencer al gañán. Soy de V. S. D. el Pensador Mexicano.

\section{Anuncio}

Está Periquillo para ver la luz pública. Se suplica a las personas que traten de subscribirse a dicha obrita, lo verifiquen en este mes en el puesto de la Gaceta, pues con sus auxilios se cuenta para emprender su impresión, y que salga en el día prefixado en el Prospecto.

\section{NOT A S}

1 Son de letra distinta. Es probable que la del primero sea la de un copista, y la del segundo, de Lizardi.

2 Ennest R. Moore, "Un manuscrito inédito de Fernández de Lizardi", Abside, III, núm. 11 (1939), pp 1-13, y núm. 12, pp. 1-30.

3 El preguntón al anigo de la patria y centinela contra insurgentes. En la imprenta de don Juan Bautista de Arizpe. 12 p.

4 Véase el núm. 7 de El Pensador Mexicano de 1812.

5 Terencio, Andria, I, 40-41 pp.

6 El Pensador Mexicano de 1812.

7 Probablemente Pieter van Musschenbrock (1692-1761), médico y físico holandés.

8 Pater ignoca illis necium quid faciunt. Así en el manuscrito. Debe ser: Pater, dimitte illis; non enim sciunt quid facitnt. Luc., XxIII 34.

9 Nulla salus bello pacem te posumus omne. Así en el manuscrito. Debe ser: Nulla salus bello; pacem te poscimus onnes. Virgilio, Eneida, xr, 362. 